\title{
10. Journalism's road codes: The enduring nature of common ethical standards
}

\section{ABSSIRACII}

Journalistic principles and codes of practice are manifestations of a desire to be seen as socially responsible. Their significance has never been in doubt but the failure to adhere to them has been brought into sharp public focus by the News International phone hacking scandal and subsequent investigations in to news media regulation in Britain, Australia and New Zealand. This article compares codes of practice across the English-speaking world and finds significant similarities in what is expected of professional journalists by their employers and professional bodies, although there are variations in the extent to which the principles of responsible journalism are followed. The means by which journalists and media companies are held accountable is challenging various jurisdictions. However, the principles to be followed are likely to remain unchanged because they are based on a pragmatic approach to shielding individuals from harm at the hands of journalists.

Keywords: comparative journalism, ethical codes, media regulation, newsworthiness, normativecodes, responsiblejournalism, socialresponsibility

\section{GAVIN ELLIS}

University of Auckland

TOURNALISTIC principles and codes of practice are manifestations of a desire to be seen as socially responsible. Just as shared practices contribute to the defining characteristics of an institution, so too, do shared desires. Hence journalistic ideals contribute to the news media's institutional character. Common institutional settings can be applied across those publications that harbour aspirations to produce serious journalism, but the publications within that grouping are not identical. Each has its own characteristics within the general framework. 
The professional norms by which we may judge the institutionalised nature of the journalism practised within them should be viewed on two separate planes. The first governs the behaviour of journalists as they go about their work, and the other relates to the values by which they judge news participants and newsworthiness. The first is governed by formal codes of practice and the latter by tacit processes that are part of newsroom culture. Hence, professional journalism is a complex alloy in which codified standards of conduct are only one of the constituent parts (see Berkovitz et al., 1997 pp105-254).

Codified standards vary in both form and detail, but there are clear similarities in the ethical expectations of the organisations that have created them. Figure 1 illustrates this conjunction, and suggests that not only is journalism institutionalised within the society it serves, but also that these foundations transcend international borders. In saying that, this article limits itself to the Anglo-American sphere and it must be acknowledged that political and cultural considerations create differing definitions and expectations of journalism in different societies. A trend toward global homogenisation of media (Hallin \& Mancini, 2004 p. 267; Tunstall, 1977, 2008 pp. 3-10) and the impact of the internet may serve to smooth out these differences, but nation-state and regional differences continue to influence journalistic practice (see Curran \& Park, 2000, p. 11).

\section{Methodology}

The Anglo-American 'region' embraced by this paper is cultural rather than geographic but is no less cohesive. It embraces the United States, the United Kingdom, Canada, Australia, Ireland and New Zealand. The codes included in Figure 1 are representative rather than exhaustive. Many organisations associated with journalism have formulated codes, standards or principles. They range from regulatory bodies, through unions and associations representing journalists, to individual media-owning companies or publications. Self-appointed 'watchdogs' also have developed their own criteria for standards that should be upheld. Accuracy in Media (www.aim.org) in the United States, for example, seeks to 'promote accuracy, fairness and balance in news reporting... [expose] politically motivated media bias; [teach] consumers to think critically about their news sources; and [hold] the mainstream press accountable for its misreporting'. These 'watchdogs' are, however, beyond the scope of this article. The industry-based codes studied here were chosen 
REBUILDING PUBLIC TRUST

\section{Figure 1: Common principles in Anglo-American journalism}

\begin{tabular}{|c|c|c|c|c|c|c|c|c|c|c|c|c|}
\hline & 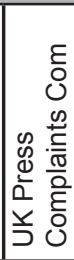 & 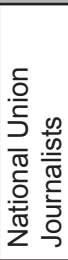 & 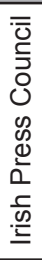 & 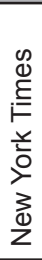 & 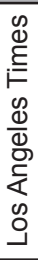 & 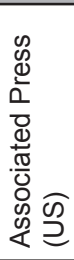 & 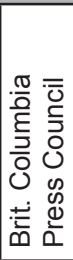 & 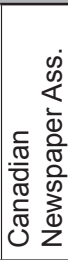 & 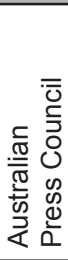 & 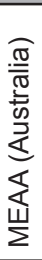 & 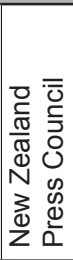 & 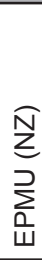 \\
\hline Accuracy & $\bullet$ & $\bullet$ & $\bullet$ & $\bullet$ & $\bullet$ & $\bullet$ & $\bullet$ & $\bullet$ & $\bullet$ & $\bullet$ & $\bullet$ & $\bullet$ \\
\hline Attribution & & & & $\bullet$ & $\bullet$ & $\bullet$ & & & & $\bullet$ & & \\
\hline Balance & & & & $\bullet$ & $\bullet$ & $\bullet$ & & $\bullet$ & $\bullet$ & $\bullet$ & $\bullet$ & $\bullet$ \\
\hline Children & $\bullet$ & & $\bullet$ & & $\bullet$ & $\bullet$ & $\bullet$ & & & & $\bullet$ & \\
\hline Confidentiality & $\bullet$ & $\bullet$ & $\bullet$ & $\bullet$ & $\bullet$ & $\bullet$ & $\bullet$ & & $\bullet$ & $\bullet$ & $\bullet$ & $\bullet$ \\
\hline Interest conflict & $\bullet$ & $\bullet$ & $\bullet$ & $\bullet$ & $\bullet$ & $\bullet$ & $\bullet$ & $\bullet$ & & $\bullet$ & & $\bullet$ \\
\hline Correction & $\bullet$ & $\bullet$ & $\bullet$ & $\bullet$ & $\bullet$ & • & • & • & • & $\bullet$ & • & • \\
\hline Discrimination* & $\bullet$ & $\bullet$ & $\bullet$ & & & & $\bullet$ & & $\bullet$ & $\bullet$ & $\bullet$ & $\bullet$ \\
\hline Fabrication** & & $\bullet$ & & $\bullet$ & $\bullet$ & $\bullet$ & & & & $\bullet$ & & \\
\hline Fairness & & $\bullet$ & $\bullet$ & $\bullet$ & $\bullet$ & $\bullet$ & & $\bullet$ & $\bullet$ & $\bullet$ & $\bullet$ & $\bullet$ \\
\hline Grief/shock & $\bullet$ & $\bullet$ & $\bullet$ & & & & & & - & $\bullet$ & $\bullet$ & $\bullet$ \\
\hline Harassment & $\bullet$ & & $\bullet$ & $\bullet$ & & & & & & & & \\
\hline Identification & $\bullet$ & & & $\bullet$ & $\bullet$ & $\bullet$ & $\bullet$ & & & $\bullet$ & & $\bullet$ \\
\hline Privacy & $\bullet$ & $\bullet$ & $\bullet$ & $\bullet$ & & $\bullet$ & $\bullet$ & $\bullet$ & $\bullet$ & $\bullet$ & $\bullet$ & $\bullet$ \\
\hline Right of reply & $\bullet$ & & & $\bullet$ & $\bullet$ & $\bullet$ & $\bullet$ & $\bullet$ & $\bullet$ & $\bullet$ & $\bullet$ & \\
\hline Sex victims & $\bullet$ & & & & $\bullet$ & $\bullet$ & $\bullet$ & & & & & \\
\hline Subterfuge & $\bullet$ & $\bullet$ & $\bullet$ & $\bullet$ & • & & $\bullet$ & & $\bullet$ & $\bullet$ & $\bullet$ & \\
\hline Treating & & & & $\bullet$ & $\bullet$ & $\bullet$ & & & & & & $\bullet$ \\
\hline
\end{tabular}

Note: * Includes communal tension ** Includes plagiarism

because they are (a) influential in their own countries and (b) are indicative of the principles deemed important in those territories. Journalists' union codes in North America have not been included because the movement there is more diverse than in Britain, Australia and New Zealand where single unions tend to dominate the profession. ${ }^{1}$ 


\section{Review}

There is a universal belief in the principle of accuracy, with its attendant principles of error correction and right-of-reply. ${ }^{2}$ Fairness, privacy rights, and the protection of confidential sources are equally binding. There is a universally-accepted need for journalistic honesty that is bound up in principles of source attribution, reporter identification, prohibitions on story fabrication and plagiarism, the avoidance of conflicts of interest and bans on treating (receiving gifts or inducements), and the use of subterfuge. ${ }^{3}$ Many codes also contain endorsements of media freedom, and freedom of expression that do not so much bind the media as send signals to those who might constrain it. They have not been included in the table, because in a free society, they should be assumed as basic human rights.

The gaps that appear in the table should not be taken as an organisation's abrogation of the relevant principle. In some codes, broad concepts such as 'honesty' and 'respect' are used to impose ethical constraints that are more closely defined in other guidelines. Some codes are silent where legislation imposes constraints, for example, on reports about the victims of sexual crimes and on discrimination. Several codes, such as that of the Canadian Newspaper Association, are overlays on guidelines developed by other organisations and do not seek to be exhaustive. In no jurisdiction is the practice of journalism subject to a single set of principles. Organisations have developed codes to meet their particular needs, but while they may differ in form, their substance tends to follow a common line. Many have submitted themselves to the disciplinary oversight of either government-ordained bodies (in the case of broadcasting) or self-regulating press complaints organisations. Such oversight has served to impose industry-wide standards, and cross-pollination between jurisdictions has further cemented the ethical bonds between journalists and between media organisations in the Anglo-American domain.

Codes and guidelines are not seen as entirely immutable. Elements have been introduced in response to circumstances. For example, privacy provisions were expanded in the face of growing calls for a legal tort to protect the rights of individuals and prohibitions on fabrication appeared in a number of jurisdictions after high-profile cases of journalistic transgression. It is rare however, for existing ethical provisions to be removed. The broadcasting industry, overseen by government-sanctioned regulatory bodies, is particularly prone to burgeoning lists of principles, guidelines, and protocols that are mixed with other aspects of programme production and presentation. 
Codes of conduct are somewhat easier to cross-reference than the practices that govern the way the news is produced. There is no standard manual. Newsrooms have their idiosyncrasies, and much of the on-the-job training that supercedes journalism degrees is a process of osmosis through which inductees absord newsroom culture and folklore. There are also organisational differences between newsrooms that follow the British tradition (United Kingdom, Ireland, Australia, and New Zealand) and those that follow the American system (United States and Canada). Together these factors constitute what Soloski terms 'intraorganisational controls' (1997, pp. 146-152). Nevertheless, these are variations in organisational structure rather than significant dissimilarity in news values and decision-making.

Galtung and Ruge's 1965 study of news values led to a general acceptance that selection criteria are common across news media and across (some) national borders. ${ }^{4}$ Certainly, 40 years of scholarship on Anglo-American journalism broadly accepted the applicability of Galtung and Ruge in understanding why certain stories are chosen and treated in certain ways. McGregor, in a 2002 analysis of New Zealand media augments Galtung and Ruge with a perceptive addendum that adds visualness, emotion, conflict, and journalist celebrification to their more prosaic list. My own experience persuades me, that while editors have not sat with a Galtung and Ruge et al. checklist at their elbows, newsroom culture has been deeply inculcated with those selection triggers through processes of observation and instruction on 'what is news'.

Brighton and Foy (2007) call for a rewriting of Galtung and Ruge's news values for the 21 st century, but perhaps their most telling insight (because it drives home the tacit nature of many institutionalised elements of journalism) is in their ultimate paragraph:

Reiterating what has been said to both authors on countless occasions during the research process of this book, the response to the question 'why is this news?' may well remain: 'It just is!' (Brighton \& Foy, 2007, p. 194)

McGregor's addendum and Brighton and Foy's 21st century update are two examples of a broad body of literature attesting to the changes that have taken place in news values over time. Hallin's encapsulation of the commercialisation of news (1992 pp. 273-282) signals 'the passing of high modernism in American journalism' and places newspapers in the 'calm before the 
storm' which subsequent scholarship would suggest has climbed ever further up the Beaufort scale. It is however, a common characteristic of this literature that changing values are applied universally. Where individual media organisations are singled out, their excesses are seen as matters of degree rather than wholesale departures from the common values shared with other news media. The broad application is valid even given variations within the media. Indeed, unintentional vanguard processes see one media organisation add new elements to its selection and presentation process only to have them subsequently replicated, often unconsciously, by its competitors. Over time, the innovations become part of the panoply of news values and good examples of isomorphic institutional change. ${ }^{5}$

Nevertheless, it is undeniable that (in spite of shared institutional bonds and the effects of homogenised news), publications (and broadcasters) differ from one another. Part of this heterogeneity is due to the pursuit of discrete market segments: the New York Times seeks a different audience to that of the New York Post while the Sydney Morning Herald positions itself in a different part of the Sydney market than that served by the Daily Telegraph. Each offers content and presentation in keeping with its readers' expectations. Part of the difference is due to no more than the desire to be different — what their marketing departments describe as their 'unique selling proposition'. However, part of the distinction is deep-set in the internal culture that once was known as the newspaper's 'heart'.

This distillation of identity is borne of tradition. A newspaper may owe its 'why we're here' to those described by Meyer (2004, pp. 204-5) as postPlatonic 'philosopher-kings', rich private owners whose ego-driven desire to produce newspapers of influence was matched by their public-spirited outlook. It may owe it to an inspired editor, such as The Guardian's C.P. Scott, whose stamp remains visible long after the chair is vacated. It may be, like most traditions, accrued identity based on the publication's finer moments. In rare instances, it may be a deliberate articulation of guiding aspirations to meet perceived public needs, such as the 'principles' bequeathed to the Toronto Star by its publisher, Joseph Atkinson (whose desire to pass ownership to a charitable trust was thwarted by Ontario law). In others it may be the long-term influence of a family: the Sulzbergers at the New York Times, the Grahams at the Washington Post, the Harmsworths at the Daily Mail, the Fairfaxes at the Sydney Morning Herald and the Hortons at the New Zealand Herald. 
Or it may be the pervasive influence of one person: Rupert Murdoch is not the archetype - he is in the tradition of Hearst, Northcliffe and Beaverbrook - but he has been the most recent manifestation. Whatever its genesis, tradition is an intangible presence akin to personal self-esteem.

Like self-esteem, it can be damaged. Conglomeration and the intrusion of management and marketing into the newsroom, have been admirably chronicled by Underwood (1993) and are exemplified by the Los Angeles Times' 1999 Staples revenue-sharing scandal in which an apparently independent editorial project celebrating the opening of a new stadium was compromised when editorial staff learned, shortly before publication, that the management of the newspaper had agreed to split the revenue from the special issue of its Sunday magazine with the stadium owners. The newspaper's credibility was damaged and its management humiliated by the scandal. Episodes such as this have called into question both a newspaper's identity and its integrity, the importance of which can be discounted by executives whose worldview is squeezed into a particular corporate - and financial — mould.

Financial crises have sent some newspapers into cardiac arrest, to live on (after highly-intrusive surgery and the effects of infarction) with an impaired ability to fulfil some of the functions upon which their identity has rested. It is a process described by former Los Angeles Times editor, John Carroll, as 'a crisis of the soul' (2006). From 2004 onward the Los Angeles Times, which had been sold to the Tribune Company in 2000, was subjected to what Carroll called 'incessant cost-cutting' and an 'unquenchable desire to measure success by the accountant's ledger' (Auletta 2007, pp. 190-212) that led to the resignation of Carroll and several other editorial executives.

The crisis of which Carroll speaks is now endemic in Anglo-American print journalism, evidenced by wave upon wave of redundancies such as those announced in June 2012 by both Fairfax and News Corporation in Australia. The cause of this recent wave, according to executives from both groups, is the need to recognise the effects of digital convergence. Jenkins divides convergence theorists into two groups: Utopians and Critical Pessimists (2006, pp. 247-8). Utopians will see the Fairfax moves, for example, as reflecting the changing nature of news consumption now that 65 percent of readers access the Sydney Morning Herald and its Melbourne stable-mate, The Age, in digital form. Critical Pessimists will see the restructuring as fewer journalists meeting increased demands, fewer 'voices' through combined functions, and a danger 
of PR release 'churnalism' through the demands of high through-put of news. Both schools, however, will agree that the Anglo-American news media (and newspapers in particular) are now in intensely competitive environments in which the largest media conglomerates now serve audiences that are 30 to 60 percent smaller than they were 25 years ago (Picard, 2010, p. 23).

\section{Discussion}

It is in this environment that the News International London tabloids - and perhaps others-lost sight of their social (and legal) responsibilities and indulged in grossly invasive breaches of ethical standards is search of exclusive stories with which to beat the competition. It led to the closure of the News of the World (to be cynically followed in short order by the launch of the Sun on Sunday), the arrest of Sun executives and journalists, and the establishment of the Leveson Inquiry. The British scandal drew attention elsewhere to the issue of media regulation and in Australia the Finkelstein Inquiry released its report in February 2012, two months after a New Zealand Law Commission discussion paper addressed media regulation in that country. In both Australasian cases, there was an acknowledgement of the common basis of many of the ethical standards to which journalists were bound. Finkelstein's report acknowledged common ground 'among all those who think seriously about the role of the news media and about journalistic ethics' and listed six areas of agreement from press freedom to codes of ethics (2012, p. 7).

In fact, these enquiries seek to confront not the 'what' but the 'how'-how can journalists be held accountable for meeting the standards demanded of them? While the Leveson inquiry had not reported when this article was written, it is reasonable to suggest that it, like those that have already reported, will not seek to redefine the ethical standards and social responsibilities for which journalists should be held accountable. The 18 areas of responsibility set out in Figure 1 will continue to be the basis on which professional journalism is practised. The standards themselves will go unchallenged because the protection they provide has a strong foundation, stretching back a century, in which philosophical principles and practical applications were fused together early in the process.

Most of the standards applied today are to be found in the earliest formal codes or 'canons' as they were termed. There was a flurry of activity in the United States in the first decades of the 20th century to draw up codes of 
ethics. The prevailing rationale in these codes related to the maintenance of truth, justice and trust. The earliest, adopted by the Kansas State Editorial Association in 1910, applied standards to newsgathering that related to truthfulness, accuracy, balance, impartiality, conflict of interest, deception and privacy. It was followed in 1921 by the Missouri Press Association's Declaration of Principles and Code of Practice which set out the following creed: 'In every line of journalistic endeavour we recognise and proclaim our obligation to the public, our duty to regard always the truth, to deal justly and walk humbly before the gospel of selfless service'. The Oregon Code of Ethics for Journalism, adopted by the Oregon Newspaper Conference the following year, contained seven articles:

- Sincerity and truth.

- Care, competency and thoroughness.

- Justice, mercy and kindliness.

- Moderation, conservatism and proportion.

- Partisanship and propaganda.

- Public service and social policy

- Advertising and circulation.

Within the seven articles are 32 specific provisions which, although couched in the more stilted language of a bygone age, could stand today as a workable code of ethics. The code required, for example, that members 'put accuracy above all other considerations in the written word, whether editorial, advertisement, article, or news story'. It also required them to 'deal by all persons alike so far as is humanly possible' and to 'consider all that we write or publish for public consumpotion in the light of its effect upon social policy, refraining from writing or from publishing if we believe our material to be socially detrimental'.

When the Hutchins Commission on Freedom of the Press in America reported in 1947, it did not take issue with the principles embodied in such codes but had a somewhat jaundiced view of their application. 'The press,' it stated, 'must know that its faults and errors have ceased to be private vagaries and have become public dangers.' The commission urged the press to accept their social responsibility and noted that 'the legal right (to press freedom) will stand if the moral right is realised or approximated' (1947, p. 230). From the commission's report flowed the phrase-and the mantra subsequently adopted by American newspapers - of 'a free and responsible press'. In the 
post-Hutchins environnment, which was matched by heightened scrutiny of the press in Britain, codified standards became an accepted part of newsrooms, media industry associations and journalists' unions.

However, I do not believe that the continuing acceptance of the adequacy of these codes is derived principally from acknowledgement of the important but intangible concepts of truth, justice and trust bound up with democratic tenets of 'the public's right to know' and 'the public interest'. Rather, their durability lies in the fact that these philosophical concepts have been translated into pragmatic terms that have greater utility in the practical, distinctly non-metaphysical, world of working journalists and Joe Public.

The word 'utility' is significant: There is a Millian thread that runs through the principles common to modern codes. All are based on the assumption that failure to observe their provisions could result in harm to an individual or group of individuals (including society in general). Mill believes 'that the only purpose for which power can be rightfully exercised over any member of a civilised community, against his will, is to prevent harm to others'. He also held that 'the beliefs which we have most warrant for, have no safeguard to rest on, but a standing invitation to the whole world to prove them unfounded' (1998, reprint). Together, these principles of harm and free expression maintain an internal consistency that suits both journalists and gatekeepers.

The working journalist and Joe Public are no more likely to resort to John Stuart Mill to resolve their differences than they are to draw on equally applicable Kantian principles in any dispute. Rather they seek an easily-understood application which is not complicated by the overt acknowledgement of philosophical underpinnings. Journalists and the public are prepared to accept those foundations and see no reason to challenge the definitional basis of 'truth', 'accuracy' or 'the public interest' even though philosophers see the concepts as deliciously contestable. They are content to accept that there are elements to the practice of journalism that have the potential to damage if its practitioners stray outside certain boundaries and practices. Hence practicality is embodied in the codes to make them both accessible and focussed on protection.

Some provisions in codes of ethics reflect a need to protect the vulnerable; some seek accuracy and equity because failure to provide it may have harmful consequences; while others impose moral standards to prevent corruption, exploitation and coercion. In each, however, there is recognition of the potential for a journalist's actions to cause harm. There is also implicit 
acknowledgement of the power relationship that exists between journalists and the public, a relationship in which the journalist is deemed to have the upper hand. Even the over-arching 'good' that the news media represent as actors in and guardians of 'the public interest' is tempered by the recognition that the boundaries set on the pursuit of this 'good' exist because to go beyond them risks unwarranted harm-to individuals and, in extreme cases, even to the fabric of society.

\section{Conclusion}

So long as the guiding principles are sufficient to keep that power in check by avoiding harmful consequences - and that appear to be the case - they will not be fundamentally challenged. Change will be limited to amendments to the detail to accommodate, for example, technological developments such as smart mobile telephones. The various regulatory reviewers instead limit themselves to the equally challenging task of finding a robust way of enforcing existing standards because there are high stakes in unravelling and re-knitting basic journalistic tenets. They are too well-established, and too bound up in accepted wisdom on human rights and democracy, for all but the very brave to do anything but leave well enough alone.

And Mill's utilitarian accommodation of the principles essential to journalism fulfilling its civic purpose provides a rationale against which it is difficult to argue. The press, on the one hand, routinely accept the 'open invitation' to place beliefs under scrutiny (and in so doing provide forums for free expression and represent a warranted de facto constraint on the power of the state) while, on the other, accept the need to have their own actions circumscribed to avoid unwarranted harm to individuals. It is a virtuous circle.

\section{Notes}

1. Irish journalists are covered by the UK-based National Union of Journalists.

2. Absent from the NUJ code because it is a decision for editors, usually outside the trade union ranks.

3. Dispensations for the use of subterfuge are generally made in codes, which acknowledge its use in investigative reporting when no other means of obtaining information is available and the matter is manifestly in the public interest.

4. Galtung and Ruge use foreign news content of Norwegian newspapers for their study, which was subsequently applied in other jurisdictions. The news criteria they list are: Relevance, timeliness, simplification, predictability, unexpectedness, 
continuity, composition, élite peoples, elite nations, and negativity. They also apply a number of qualifiers to their list of news values.

5. The concept of institutional isomorphism developed by Powell and DiMaggio is apparent in the news media. Their research describes coercive, imitative, and normative processes that create, maintain, and change in organisations. Coercive isomorphism results from both formal and informal pressures exerted on organisations by other organisations upon which they are dependent and by cultural expectations in the society within which organisations function (1983, pp. 150-154).

\section{References}

Annals of the American Academy of Political Social Sciences, 101(May 1922), 283295.

Auletta, K. (2007). Can the Los Angeles Times survive its owners? In Madigan, C. M. (Ed.), The Collapse of the Great American Newspaper (pp. 190-209). Chicago: Ivan R. Dee.

Berkowitz, D. (Ed.) (1997). Social meaning of news: A text-reader. Thousand Oaks, CA: Sage.

Brighton, P. and D. Foy. (2007). News values. London: Sage.

Carroll, J. (2006). Speech to the American Society of Editors, April 26.

Curran, J. and M. Park (Eds.) (2000). De-westernizing media studies. London: Routledge.

Finkelstein, R. (2012). Report of the independent inquiry into the media and media regulation. Canberra: Commonwealth of Australia.

Galtung, J., and M. H. Ruge. (1965). The structure of foreign news. Journal of Peace Research, 2, 64-91.

Hallin, D. C. and P. Mancini. (2004). Comparing media systems: Three models of media and politics. Cambridge: Cambridge University Press.

Hocking, W. E. (1947). Freedom of the press: a framework of principles (A report of the Commission on Freedom of the Press). Chicago: University of Chicago Press.

Jenkins, H. (2006). Convergence culture. New York: New York University Press.

McGregor, J. (2002). Restating news values: contemporary criteria for selecting the news. In ANZCA. Coolangatta: Massey University.

Meyer, P. (2004). The vanishing newspaper: Saving journalism in the information age. Columbia, MO: University of Missouri Press.

Mill, J. S. (1998, Reprint Edition). On Liberty and other essays. Oxford: Oxford University Press.

Picard, R.G. (2010). A business perspective on challenges facing journalism. In D. A. L. Levy and R. K. Nielsen (Eds.), The changing business of journalism and its implications for democracy (pp. 17-24). Oxford: Reuters Institute for the Study of Journalism.

Powell, W. E. and P. J. DiMaggio. (1983). The iron cage revisited: Institutional isomorphism and collective rationality in organisational field. American Sociological Review, 48(2), pp. 147-160. 


\section{REBUILDING PUBLIC TRUST}

Soloski, J. (1997). News reporting and professionalism. In Berkowitz, D. (Ed.), Social meaning of news: a text-reader (pp. 138-154). Thousand Oaks (CA): Sage.

Tunstall, J. (1977). The media are American. New York: Columbia University Press. Tunstall, J. (2008). The media were American. New York: Oxford University Press. Underwood, D. (1993). When MBAs rule the newsroom: How the marketers and managers are reshaping today's media. New York: Columbia University Press.

\section{Codes of Practice may be found at the following websites:}

Australian Press Council: www.presscouncil.org.au/statements-of-principles/

British Columbia Press Council: www.bcpresscouncil.org/code.html

Canadian Newspaper Association: www.newspaperscanada.ca/about-newspapers/ statement-principles

Irish Press Council: www.presscouncil.ie/code-of-practice.150.html

Los Angeles Times Tribune Company: latimesblogs.latimes.com/readers/2007/07/ los-angeles-tim.html

Media Entertainment and Arts Alliance (MEAA, Australia):www.alliance.org.au/ code-of-ethics.html

New York Times Company: www.nytco.com/pdf/NYT_Ethical_Journalism_0904.pdf

New Zealand Press Council: www.presscouncil.org.nz/principles.php

NZ Amalgamated Engineering, Printing \& Manufacturing Union (EPMU):

www.epmu.org.nz/journalist-code-of-ethics/

UK National Union of Journalists: www.nuj.org.uk/files/NUJ_Code_of_Conduct.pdf UK Press Complaints Commission: www.pcc.org.uk/cop/practice. $\overline{\mathrm{htm}} \overline{\mathrm{l}}$ United States Associated Press: www.ap.org/company/News-Values

Dr Gavin Ellis is a senior lecturer in political studies at the University of Auckland. He has a background of more than 40 years in journalism and retired from the position of editor-in-chief of The New Zealand Herald and Weekend Herald in 2005. gavin.ellis@xtra.co.nz 
Copyright of Pacific Journalism Review is the property of Auckland University of Technology and its content may not be copied or emailed to multiple sites or posted to a listserv without the copyright holder's express written permission. However, users may print, download, or email articles for individual use.

http://www.aut.ac.nz/depts/commstud/journ/pjrsubs.shtml 